\title{
CULTURA ORGANIZACIONAL: GENERALIZAÇÕES IMPROVÁVEIS E CONCEITUAÇÕES IMPRECISAS
}

RESUMO

Neste artigo buscamos problematizar, por meio da perspectiva epistemológica pós-moderna, parte da produção nacional de pesquisas e estudos sobre cultura organizacional brasileira. Para tanto, primeiramente apresentamos aspectos da perspectiva pós-moderna de análise, focando em suas contribuições para o estudo da cultura nas organizações. Em seguida, desenvolvemos uma breve apresentação das idéias centrais de artigos publicados em periódicos e congressos nacionais, no período de 1991 a 2000, que versaram sobre cultura organizacional brasileira, buscando traçar suas características fundamentais. Com base nesse quadro de referência, concluímos que a maioria dos estudos sobre cultura brasileira desenvolvidos no âmbito da administração analisa o tema de forma homogênea, não levando em conta a pluralidade e a heterogeneidade de nosso país e de nossas organizações.

\section{Rafael Alcadipani \\ FGV-EAESP e ESPM-SP}

\section{João Marcelo Crubellate}

FGV-EAESP e UEM

\footnotetext{
ABSTRACT Based on a post-modernist perspective, this paper problematizes the Brazilian academic production on organizational culture. Firstly, we present some important aspects of the post-modernist perspective in social theory, focusing on its contribution to the study of organizational culture. Then, we briefly present some central ideas developed in papers on Brazilian organizational culture published in Brazilian journals and conferences proceedings during the years 1991 to 2000. Based on this theoretical and empirical reference, we finally conclude that most of the studies and researches on Brazilian organizational culture, in the context of Administrative academic field, do not appropriately consider the plurality and heterogeneity of our country and our organizations.
}

PALAVRAS-CHAVE Cultura brasileira, cultura organizacional, pós-modernismo, antropologia, crítica. KEY WORDS Brazilian culture; organizational culture; post-modernism; Antropology; critique. 


\section{INTRODUÇÃo}

Nosso país é nitidamente plural. Fomos colonizados oficialmente por portugueses e tivemos fortes influências negras e indígenas, sem falar nos diversos povos - italianos, japoneses, franceses, holandeses, árabes, entre muitos outros - que ao longo de nossa história vieram para o Brasil. Assim, este país é um caleidoscópio de povos e etnias. Somando-se a isso, ele tem passado por diversos processos econômico-culturais. Por tais razões, o Brasil é um dos mais diversos e heterogêneos países do mundo (Ribeiro, 1995). Basta andarmos um pouco por nossas cidades e diferentes regiões para que esse fato fique patente. No que diz respeito às organizações, tal constatação repete-se, pois temos dentro de nossas fronteiras geográficas desde empresas semi-artesanais e fazendas com mão-de-obra ainda escrava até empresas de altíssima tecnologia.

Diante desse caleidoscópio social, étnico e cultural, será que as organizações brasileiras possuem uma cultura claramente decifrável, dotada de traços que poderiam ser evidenciados pelo simples fato de estarem dentro das fronteiras geográficas do país? Se analisarmos, a partir de uma perspectiva pós-moderna, a maioria das pesquisas e estudos em análise organizacional que buscam explorar a suposta influência da cultura brasileira na cultura das organizações locais, a resposta parece ser negativa.

A perspectiva pós-moderna ganhou fôlego e destaque na análise das organizações (Cooper e Burrell, 1988; Calás e Smircich, 1999) e vem sendo utilizada como matriz epistemológica para a discussão sobre cultura, tanto na Antropologia (Clifford e Marcus, 1986; Rabinow, 1999; Gonçalves da Silva, 1999) quanto na teoria organizacional (Alvesson e Berg, 1992; Martin, 1992; Martin e Frost, 2001; Prasad e Prasad, 2001).

Frente a isso, o objetivo deste artigo é analisar a produção que versa sobre cultura organizacional brasileira em administração e tentar problematizar, a partir de um espírito de análise pós-modernista, a suposição de uma cultura organizacional brasileira decifrável e única, gerada a partir da influência dos supostos traços culturais brasileiros sobre as organizações. Para tanto, na primeira parte, apresentaremos os principais preceitos da perspectiva epistemológica pós-modernista, sua influência na análise organizacional de forma ampla e nos estudos sobre cultura organizacional em particular. Na segun$\mathrm{da}$, apresentaremos os principais estudos e pesquisas que versam sobre a influência da "cultura brasileira" na cul- tura das organizações, buscando traçar suas principais características. Na terceira parte, tentaremos analisar os estudos citados à luz da perspectiva pós-moderna. Por fim, faremos nossas considerações finais.

\section{PÓS-MODERNISMO E CULTURA ORGANIZACIONAL}

As categorias de classificação "pós-moderno" e "pósmodernismo" podem ser vistas como possuidoras de diferentes significados. Por exemplo, podem ser encaradas como um movimento artístico e uma nova matriz epistemológica (Hassard, 1993), como características de um novo tipo de sociedade (Bauman, 1988a, 1988b) e como um novo tipo de organização (Clegg, 1990). Trata-se de uma categoria bastante ampla, carente de unidade conceitual, e que pretende ser muitas coisas ao mesmo tempo. Tentando deixar seus significados um pouco mais claros, Parker (1992) discute a diferença entre pós-modernismo e pós-modernidade no campo específico da análise organizacional. O autor sugere que o prefixo "pós" está relacionado a um universo de conceitos, tais como pós-industrial, pós-fordismo, pós-capitalismo etc. Esses conceitos refletem feições características da pós-modernidade entendida como uma nova época histórica em curso. Por isso, para aquele autor, pós-modernidade significaria a época que sucede à modernidade, ou seja, é a expressão de um novo período histórico que pode ser analisado a partir das ciências "modernistas". A noção de pós-modernidade, por sua vez, segundo Parker (1992), refere-se a uma epistemologia que representa uma forma diferente do modernismo e de suas vertentes científicas de pensar e pesquisar a sociedade e, conseqüentemente, as organizações. O foco do presente artigo está centrado na segunda noção, ou seja, na pós-modernidade em termos epistemológicos, que passaremos a discutir.

As idéias de autores como Boudrillard, Lyotard, Derrida e Foucault, tidos como pós-modernos, têm sido utilizadas desde o final dos anos 1980 nas Ciências Humanas por representarem uma forma diferente de pensar e de refletir sobre a sociedade (Bauman, 1988a, 1988b; Featherstone, 1988). Especificamente, o pósmodernismo é formado por uma pluralidade de conceitos abordados por autores que apresentam idéias distintas e complexas. Todavia, há alguns traços gerais nessa forma de refletir sobre a "realidade" social.

Fundamentalmente, os pensadores pós-modernos não acreditam na primazia da razão humana e no homem 
racional, tampouco no progresso intelectual. Eles não consideram o homem como o centro do mundo e sua razão como absoluta. A própria realidade possui seu status ontológico questionado. Ela é vista como multifacetada, ambígua, não podendo ser explicada por totalidades ou modelos. Por isso, não concordam com pensamentos totalizantes ou sistêmicos para explicar a realidade, ou seja, matrizes de input/output que seguem uma lógica a qual implica a comensurabilidade dos elementos e a determinação do todo (Lyotard, 1989). Pensamentos desse tipo são vistos como metanarrativas de verdade e generalizações simplificadoras. Em contrapartida, a diversidade, a ambigüidade e as pluralidades são tratadas como elementos fundamentais do mundo social.

Dentro desse contexto, a noção de verdade é problematizada por esses pensadores. Ela é apontada como dependente das circunstâncias específicas de cada período histórico e das relações de poder envolvidas no contexto de sua geração, relações estas necessárias à sua manutenção. Ou seja, os regimes de verdade são apontados como sustentáculos das relações de poder ao mesmo tempo em que são sustentados por elas (Foucault, $1966,1987)$. As verdades não são vistas como certas ou erradas, boas ou más, ou seja, não há preocupação com valorações morais, vistas como precárias e incertas. Para a perspectiva pós-modernista, o sujeito não é apresentado como um dado absoluto e como tendo uma essência verdadeira que está "escondida" ou "reprimida". Ele é visto como construído e reconstruído dentro das relações de poder e contextos sociais a que está submetido (Foucault, 1987). O poder, por sua vez, não é encarado como algo facilmente localizável ou que é possuído por alguém que o utiliza a seu bel-prazer. Ele é visto como um feixe de estratégias anônimas, sem possuidores, cujas relações são formadas e reformuladas a cada momento (Foucault, 1987). Simplificando ao máximo, entende-se por pós-modernismo a incredulidade com respeito às metanarrativas e às generalizações totalizantes (Lyotard, 1989).

Vale destacar que essa perspectiva vem recebendo críticas de diversos autores nas Ciências Sociais e na filosofia da ciência, de forma geral (Habermas, 1981; Sokal e Bricmont, 1999), e nos estudos organizacionais e administrativos, em particular (Thompson, 1993). As mais relevantes são: (1) os teóricos pós-modernistas, ao criticarem as generalizações e as metanarrativas, acabam por fazer o que criticam, e (2) a perspectiva pós-modernista carece de fundamentação, configurando-se como um conjunto de idéias sem o menor rigor científico.
Em termos de análise organizacional, a utilização das idéias pós-modernas, a partir do final da década de 1980, aumentou significativamente tanto o debate epistemológico quanto metodológico na área (Cooper e Burrell, 1988; Hassard, 1993; Calás e Smircich, 1999).

No caso específico das análises sobre cultura organizacional, o pós-modernismo manifesta-se como movimento que questiona e problematiza as teorias e os estudos realizados a respeito do tema (Martin e Frost, 2001; Alvesson e Berg, 1992). Para os defensores da perspectiva pós-moderna, os estudos culturais modernos, mesmo aqueles que adotam um ângulo antropológico ou crítico de análise, tentam oferecer relatos coerentes para interpretar a vida organizacional, havendo uma nítida busca por interpretações generalizáveis. Nessa tentativa, acabam atropelando peculiaridades, nuanças e especificidades do objeto que analisam (Martin e Frost, 2001). A perspectiva pós-moderna de um modo geral, e aplicada à análise da cultura das organizações em particular, procura evidenciar os problemas relacionados às interpretações generalizáveis, à "ditadura" do autor e à imposição de pressupostos assumidos como verdadeiros sobre o fenômeno social. Pretende, assim, explorar os paradoxos e as ambigüidades presentes na retórica, desnaturalizando a realidade (Alvesson e Berg, 1992).

Ademais, os pós-modernistas questionam a existência de significados estruturados, "obscuros" e "profundos", argumentando a impossibilidade de localizá-los. Tais significados, para essa perspectiva, não possuem conexões, ou ao menos conexões triviais, com sentidos que supostamente deveriam representar. Isso implica a negação de uma estética, de uma moral, de estruturas sociais pressupostas e de esquemas interpretativos de segunda ordem, como a cultura corporativa (Alvesson e Berg, 1992). A cultura organizacional é vista como fragmentação (Hatch, 1997), ou seja, uma teia de indivíduos conectados fraca e esporadicamente, ligados por suas posições cambiantes em uma variedade de assuntos e circunstâncias. Seus envolvimentos, suas identidades subculturais e suas autodefinições individuais são flutuantes e dependentes do assunto em que estão atuando em um dado momento e do contexto específico em que estão inseridas (Martin, 1992). Ou seja, a cultura depende do contexto momentâneo. Além disso, a ambigüidade é apontada como característica fundamental da cultura organizacional. As fronteiras das subculturas são vistas como altamente permeáveis e flutuantes. Ela e suas manifestações são apontadas como multifacetadas, sendo seus significados 
necessariamente abertos a múltiplas interpretações. Assim, a realidade cultural é formada por complexidade, multiplicidade e fluxos contínuos e mutáveis, não sendo definida claramente a priori (Martin, 1992; Alvesson, 1995; Hatch, 1997).

Um ponto a se destacar dentro dessa perspectiva é de que ela não apresenta o sujeito como possuidor de uma identidade fornecida pela cultura, e contra a qual é muito difícil escapar. Ou seja, não é porque o sujeito trabalha em uma dada organização, em um departamento específico ou é proveniente de um determinado grupo da empresa que ele deverá se comportar como os demais por pertencer a uma mesma "dada cultura". Segundo essa perspectiva, a cultura não define um sujeito, nem predetermina suas ações e atitudes (Martin, 1992; Alvesson, 1995; Hatch, 1997).

Uma vertente que vem ganhando fôlego dentro dos estudos pós-modernistas em cultura organizacional é o pós-colonialismo, que denuncia a epistemologia e muitas práticas ocidentais como sistemas de exclusão de outras realidades e de outras formas de conhecimento (Calás e Smircich, 1999; Prasad e Prasad, 2001). Uma temática bastante recorrente nessa vertente é a crítica das noções de "progresso" e de "modernidade" conceituadas por teóricos de países desenvolvidos. De acordo com os pós-colonialistas, essas noções focam, via de regra, aspectos econômicos, e mostram o acesso e o progresso da ciência e da tecnologia como justificativas do "desenvolvimento" de alguns países e do não desenvolvimento de outros. O desenvolvimento dentro dos parâmetros da cultura ocidental dos países ricos acaba por relacionar povos e culturas dos países "emergentes" como sendo "não desenvolvidos" ou "primitivos", gerando a exclusão de seus saberes, valores e culturas. Há, ainda, uma crítica aos pesquisadores do Terceiro Mundo que utilizam seu espaço para dar voz à teoria, que os exclui, gerada no mundo desenvolvido. Tomando como foco de análise a denúncia das estratégias pós-colonialistas, a cultura popular e os movimentos sociais, esses teóricos tentam dar espaço àquelas vozes até então excluídas (Calás e Smircich, 1999).

Pelo exposto, podemos perceber a precariedade com que é vista a noção de cultura organizacional dentro da perspectiva pós-modernista. Assim, utilizaremos os aspectos aqui apresentados dessa perspectiva para analisar os estudos que retratam uma "cultura organizacional brasileira”, objeto do próximo item. Além disso, também utilizaremos autores que tratam da realidade de "nossa cultura" para discutir e problematizar alguns aspectos que levantaremos a seguir.

\section{PESQUISA E ESTUDOS SOBRE CULTURA ORGANIZACIONAL BRASILEIRA EM ADMINISTRAÇÃO}

Neste item, apresentaremos os estudos e pesquisas que versam sobre a influência da "cultura brasileira" na cultura das organizações. Para facilitar a organização do texto, focaremos primeiramente os procedimentos de coleta de dados. Logo a seguir, mostraremos os dados de nossa pesquisa por ordem temática: primeiro apresentaremos os textos que versam sobre a noção de cultura organizacional brasileira de forma ampla e, depois, os textos que sugerem a influência de traços específicos da cultura nacional sobre a cultura das organizações. Por fim, apresentaremos as características fundamentais desses estudos.

\section{Procedimento de coleta de dados}

Como o foco do artigo é a área de Administração, analisamos os artigos publicados nos periódicos Revista de Administração de Empresas, Revista de Administração, Revista de Administração Pública, Organização E Sociedade e Revista de Administração Contemporânea, além dos Anais do Enanpad e do I Encontro Nacional de Estudos Organizacionais, no período compreendido entre 1990 e 2000. Em uma análise prévia desses periódicos e anais de congressos, já havíamos constatado que a maioria das publicações sobre o assunto ocorreu na década de 1990, o que influenciou na escolha daquele período como recurso de amostragem. Optamos, igualmente, por analisar os artigos presentes no livro de Prestes Motta e Caldas (1997), bem como os livros de Hofstede (1991) e de Barros e Prates (1996), pois são referências fundamentais sobre o assunto em questão. Como o foco de análise é discutir e problematizar a noção da cultura organizacional brasileira mediante a perspectiva pós-moderna, optamos também por não realizar análise quantitativa de temáticas ou citações, mas sim análise de conteúdo (Bardin, 1977), a fim de apreender os principais argumentos utilizados pelos respectivos autores daqueles textos e que tinham relação com a questão fundamental aqui discutida - argumentos que são posteriormente problematizados.

\section{A noção de cultura organizacional brasileira}

Um dos pioneiros na discussão sobre a influência das culturas nacionais sobre as culturas das organizações foi Hofstede (1991), que, apesar de se restringir ao âmbito de uma única grande organização, a IBM, abrangeu indiretamente mais de 50 países. Para ele, cultura 
é "o programa coletivo da mente que distingue os membros de grupos ou categorias de pessoas" (Hofstede, 1991, p. 5). A partir desse pressuposto e do estudo quantitativo com funcionários de subsidiárias da IBM ao redor do mundo, ele pretendeu "identificar diferenças nos sistemas nacionais de valores" (Hofstede, 1991, p. 13), caracterizando as culturas nacionais em torno de cinco dimensões: distância do poder, coletivismo versus individualismo, feminilidade versus masculinidade, aversão à incerteza e orientação para curto ou longo prazo. Os países foram plotados em gráficos que identificavam suas posições em relação a cada dimensão. O Brasil foi identificado como um país com cultura tendente ao estabelecimento de relações de dependência ou crítica radical em relação às instâncias de poder, isto é, com elevada distância de poder; com predominância de atitudes voltadas a evitar incertezas (alta aversão à incerteza); e também com clara orientação do comportamento para o longo prazo. Além dessas dimensões, identificou-se também o padrão cultural brasileiro como mais coletivista do que individualista e identificou-se, ainda, leve predominância de características típicas da feminilidade.

O estudo de Hofstede tornou-se amplamente replicado e referenciado em artigos brasileiros, constituindo-se em forte influenciador da concepção de cultura brasileira desenvolvida em nossa teoria organizacional e administrativa. Geralmente, tais artigos propõem analisar diferenças de estilos gerenciais e explicá-los a partir das diferenças culturais nacionais apontadas por Hofstede (Urdan e Urdan, 2001; Barros e Prates, 1996). Vale frisar que os aspectos da cultura brasileira apontados por Hofstede são geralmente aceitos sem problematização.

Dentre as pesquisas em questão, uma das mais destacadas foi a realizada por Barros e Prates (1996), com o objetivo de identificar elementos e parâmetros culturais brasileiros a serem considerados tanto por dirigentes em decisões sobre a implementação de formas modernas de gerenciamento criadas em outros países quanto por dirigentes de multinacionais que buscam se adequar à nossa cultura. Os autores usaram o referencial de Hofstede e de outros autores, principalmente Roberto DaMatta e Lívia Barbosa, para tentar desvendar "o estilo brasileiro de administrar". Chegaram a construir uma proposta daquilo que acreditam ser "um modelo de ação cultural brasileiro na gestão empresarial" (Barros e Prates, 1997 , p. 55). Para tanto, realizaram pesquisa quantitativa, por meio de questionários, com 2.500 dirigentes e executivos de 520 empresas de grande e médio porte do Sul e Sudeste do país.
Os autores caracterizam o estilo brasileiro de administrar como único e original. O modelo de ação cultural brasileiro, para os autores, corresponderia a um sistema composto por quatro subsistemas, quais sejam: institucional (ou formal), pessoal (ou informal), líderes e liderados. Esses subsistemas apresentam interseções e nelas se encontrariam traços culturais comuns e que comporiam o estilo brasileiro de administrar. Tais traços seriam: (1) concentração de poder, na interseção dos subsistemas líderes e institucional; (2) postura de espectador, na interseção dos subsistemas liderados e institucional; (3) personalismo, na interseção dos subsistemas líderes e pessoal; e (4) evitar conflito, na interseção dos subsistemas liderados e pessoal. Tais traços culturais especiais seriam, em última análise, responsáveis pela não ruptura do sistema como um todo, e são eles que deveriam ser alterados em grau ou natureza para a mudança efetiva da cultura (Barros e Prates, 1996). Em resumo, os pontos críticos da cultura brasileira seriam o formalismo, a flexibilidade, a lealdade às pessoas e o paternalismo. O que garantiria o funcionamento desse sistema como um todo seria a impunidade. Assim, a alteração desse modelo passaria pela mudança ou ruptura de tais aspectos.

A fim de discutir a cultura organizacional brasileira, Aidar, Brizola, Prestes Motta e Wood Jr. (1995) realizaram um ensaio cujo objetivo principal foi analisar historicamente a formação da cultura nacional e como esta se relacionaria com valores e padrões de comportamento encontrados em nossas organizações. Os autores chegaram à conclusão de que o sistema social brasileiro é dividido e equilibrado por entidades e instâncias criadas em nossa peculiaridade e que acabam por tornar o convívio com paradoxos suportável, ao mesmo tempo em que dificultam transformações mais profundas. Constataram, também, que a pluralidade é um dos aspectos essenciais da cultura brasileira e do universo das organizações locais. Prestes Motta (1997), dentro desse contexto, analisa os autores que tratam de culturas nacionais e os autores clássicos sobre a formação da cultura brasileira - Gilberto Freire, Roberto DaMatta, Caio Prado Jr., Sérgio Buarque de Holanda e Darcy Ribeiro -, bem como psicanalistas (Calligaris, 1993) que desenvolveram investigações sobre o Brasil, e conclui que nosso país é uma terra de contrastes e que nossa cultura é marcada por heterogeneidade e complexidade, caracterizando-se como multifacetada. Ambos artigos são ensaios baseados em pesquisa bibliográfica.

Com o intuito de "criar um suporte instrumental para a análise das culturas organizacionais sob o prisma da 
cultura brasileira", Alexandre Borges de Freitas (1997) tentou elucidar traços culturais brasileiros para uma análise organizacional. Sua contribuição foi feita a partir da leitura dos clássicos que retratam a formação brasileira, de autores como Gilberto Freire, Sérgio Buarque de Holanda e Caio Prado Jr., bem como de antropólogos como Roberto DaMatta. Borges de Freitas (1997) fundamenta sua análise apenas em pesquisa bibliográfica. Muito embora reconheça o caráter diverso e heterogêneo da cultura de nosso país, o autor conclui que os traços nacionais para uma análise organizacional seriam: a hierarquia, o personalismo, a malandragem, o sensualismo e o espírito aventureiro.

Tentando elaborar uma metodologia para o gerenciamento da cultura das organizações do setor público no Brasil, Carbone (2000), com base em Hofstede e Roberto DaMatta, aponta que a cultura brasileira possui certos traços que podem dificultar a mudança das culturas de organizações públicas face ao paradigma da globalização. Tais traços seriam: burocratismo, autoritarismo, paternalismo, aversão aos empreendedores, "levar vantagem" e reformismo. Nessa mesma linha da cultura como obstáculo para a mudança, Campos (2000), a partir de Roberto DaMatta e dos traços culturais nacionais levantados por Borges de Freitas (1997), deixa subentendido que tais traços culturais típicos da cultura organizacional brasileira constituem entrave para a competitividade e o aprendizado das organizações locais. Baiardi (1997) discute as origens históricas dos padrões culturais e da resistência a mudanças em nosso país e caracteriza tais padrões como obstáculos à democracia e ao desenvolvimento nacional. Vale ressaltar que ambos estudos são ensaios teóricos. Cavedon (1998) buscou levantar os tipos de cultura presentes em organizações no Rio Grande do Sul e constatou uma ênfase em estruturas tradicionais. Com isso, descreve que estamos longe do que se apregoa como "tendências futuras".

Alguns estudos de caso também foram realizados com o intuito de analisar a influência, ou melhor, a peculiaridade de organizações tipicamente brasileiras. Lucirton Costa (1997) analisou uma organização que, acredita ele, é possível e recorrente em nosso país graças às nossas peculiaridades: a organização cordial. Embora reconheça a heterogeneidade da cultura nacional, o autor procura a identificação de traços e atitudes culturais típicas para a elaboração de um modelo de gestão nacional. A análise de uma torcida organizada de futebol permitiu a ele desenvolver a noção de organização cordial, ou seja, um tipo de organização em que a lógica de fundo emotivo está eminentemente presente na determinação das principais ações desencadeadas em seu âmbito. O artigo está embasado em pesquisa bibliográfica e em entrevistas na "Gaviões". Outro estudo de caso foi realizado por Vergara, Moraes e Palmeira (1997). Nesse artigo, os autores procuraram desvendar aspectos administrativos de uma organização tipicamente brasileira - a escola de samba - e nela identificar os aspectos da cultura nacional. Constataram, no barracão de dada escola de samba, uma característica que acreditam ser nacional, qual seja: a conjugação de elementos contraditórios, relacionada com uma constante relação entre o arcaico e o moderno. Além disso, observaram que a "casa" - locus do personalismo - é apontada como local ideal e recorrente. Santos (1996), por sua vez, analisa o modelo de uma organização de jogo do bicho na Bahia, e afirma ter encontrado naquela organização uma forma brasileira de administração eficaz, destituída dos modelos e tecnologias gerenciais importadas, na qual se encontra paternalismo, protecionismo, vícios, família, formalismo, regras, moralidade, perversidade, favor, comprometimento, "jeitinho" etc. O autor aponta que a capacidade de lidar com o diverso é o elemento fundamental do sucesso dessa organização.

Já Barros (2001) compara organizações comunitárias da Bahia e de Québec (Canadá). Em termos de traços culturais brasileiros, o autor segue o padrão tradicional de concepção altamente negativa das características culturais nacionais. São destacados aspectos como o padrão de relações afetivas ao invés de impessoais, patrimonialismo, patriarcalismo e conseqüente autoritarismo predominante nas relações profissionais, ausência de orgulho e complexo de inferioridade, tolerância e flexibilidade de costumes, frouxidão moral, irresponsabilidade social e ecológica, aversão ao trabalho etc.

\section{Traços tipicamente nacionais e cultura organizacional}

Além de todos esses estudos, foram realizados ensaios sobre a influência de traços culturais específicos e tipicamente brasileiros nas organizações. A busca da causa de sua existência remete às origens da formação nacional, conforme sugerem esses estudos. Nesse sentido, Caldas (1997) discute que "santo de casa, não faz milagre", apontando suposta "fixação brasileira" pela figura do estrangeiro. O autor tenta traçar as origens e condicionantes do estrangeirismo e sua influência nas organizações brasileiras, apontando que esse traço está "institucionalizado" em nosso país. Sugere-se que te- 
mos uma fixação pelo que vem do outro. O autor traça as origens dessa suposta fixação por meio da análise do que acredita serem seus condicionantes locais e nacionais. Analisando as conseqüências desse traço, o autor o avalia como algo negativo, "não bom" para as organizações locais. Analisando o mesmo traço cultural e sua influência nas organizações, Prestes Motta, Alcadipani e Bresler (2001) buscam suas origens históricas e discutem como ele está relacionado com o modo pelo qual as pessoas são percebidas, geridas, administradas e controladas no Brasil. Vale destacar que ambos os artigos são ensaios baseados em historiadores e antropólogos, aqui já citados, que discutem a formação nacional.

Davel e Vasconcelos (1997), por sua vez, identificam certa dimensão paterna nas organizações brasileiras, apontando a recorrência histórica dessa característica. Os autores demonstram como a função do pai está presente no ethos de uma organização familiar brasileira. Argumentam também que a figura paterna e o paternalismo são traços recorrentes de empresas que estão inseridas em uma cultura paternalista. Dentro desse mesmo foco de análise, Bresler (2000) analisa a imagem do pai na realidade brasileira, apontando que essa é uma das formas pelas quais a dominação é exercida nas organizações que atuam em nosso país. Nesse sentido, Capelão (2000) analisa a mesma característica cultural em uma empresa familiar brasileira, tentando resgatar a "genealogia" desse traço e a forma de sua manifestação na empresa estudada. Vale frisar que todos os artigos discutem as origens históricas de tal traço em nosso contexto cultural.

Por fim, Prestes Motta e Alcadipani (1999) discutem o "jeitinho brasileiro" nas organizações nacionais, apontando suas origens históricas e seus condicionantes culturais, bem como suas conseqüências. Fazem isso por meio de pesquisa bibliográfica.

\section{Características dos estudos sobre cultura organizacional brasileira}

Assim, temos de reconhecer que os artigos que versam sobre uma cultura organizacional brasileira diferem em termos de metodologia e de foco de análise, bem como de suporte teórico-conceitual. Porém, esses mesmos artigos possuem algumas características que, embora em variado grau, são recorrentes na maioria.

A primeira delas é que esses estudos são influenciados de forma marcante pela pesquisa de Hofstede, que tem seus preceitos, via de regra, aceitos de forma não problematizada. A segunda consideração é a de que temos uma maioria significativa de ensaios teóricos que recorrem à análise de traços culturais nacionais desde suas origens históricas por meio da leitura de autores nacionalmente consagrados, como Sérgio Buarque de Holanda, Caio Prado Jr., Gilberto Freire, Raymundo Faoro, Darcy Ribeiro e Roberto DaMatta, sendo que este último está presente em todas as pesquisas e estudos, não importando a perspectiva metodológica. Nesse aspecto, os artigos procuram resgatar as origens dos traços culturais desde o nascimento do Brasil até os dias de hoje, analisando, via de regra, tais características sem as devidas nuanças. Os estudos de caso estão centrados em organizações que são apresentadas como mais específicas de nossa realidade, tais como torcida organizada, escolas de samba e empresas familiares. Poucos são os estudos de caso comparativos que, em sua grande maioria, quando são realizados, utilizam-se da perspectiva de Hofstede e de sua metodologia.

A terceira consideração é de que, em maior ou menor grau, os traços culturais aparecem como abrangentes e como sendo característicos de uma unidade denominada "cultura brasileira". Vale ressaltar que Aidar, Brizola, Prestes Motta e Wood Jr. (1995) e Prestes Motta (1997) reconhecem a pluralidade da cultura nacional e levam isso em conta na construção do argumento de seus artigos. Os demais autores parecem reconhecer a heterogeneidade, mas acabam por desconsiderá-la, falando de traços culturais que valem para todo o Brasil, que surgiram em um dado contexto histórico e que chegaram até os dias de hoje sem grandes alterações ou nuanças. Este é o caso do estilo brasileiro de administrar, dos traços para a análise organizacional, do estrangeirismo e do paternalismo, discutidos anteriormente. Há clara sugestão de causação cultural, implícita ou explícita, no seguinte sentido: o Brasil possui traços culturais nítidos e decifráveis que afetam as organizações, formando uma cultura organizacional brasileira. A quarta consideração é de que são realizados juízos de valor sobre os supostos traços culturais nacionais, vistos como "subdesenvolvidos" e como causadores do atraso nacional com relação aos países desenvolvidos do mundo ocidental industrializado. Barros e Prates $(1996,1997)$ propõem, inclusive, a alteração desses traços por meio de intervenções sobre o "estilo brasileiro de administrar".

\section{O PÓS-MODERNISMO VISITA A NOCÃO DE CULTURA ORGANIZACIONAL BRASILEIRA}

Nesta parte, problematizaremos, por meio da perspectiva do pós-modernismo, as principais característi- 
cas de pesquisas e estudos sobre a existência de uma cultura organizacional brasileira. Faremos isso tentando mostrar as contradições inerentes a essas características. Vale frisar que não pretendemos com isso invalidar ou apontar a perspectiva pós-moderna como melhor do que as demais para a análise da questão da cultura organizacional brasileira, tampouco pretendemos propor uma análise da cultura organizacional brasileira utilizando o pós-modernismo. Nosso objetivo é utilizálo para problematizar os estudos sobre cultura organizacional brasileira com o intuito de contribuir para a discussão sobre essa noção, tão importante para a afirmação de pesquisa e estudos organizacionais gerados em nosso contexto.

Vimos anteriormente que, muito embora os artigos analisados divirjam em termos de metodologia, foco de análise e suporte teórico-conceitual, eles possuem algumas características recorrentes. Como destacamos, a primeira delas é de que esses estudos são influenciados de forma marcante pela pesquisa de Hofstede, que tem seus pressupostos aceitos de forma não problematizada. A segunda característica é de que, em sua maioria significativa, os textos recorrem à análise de traços culturais nacionais a partir de suas origens históricas, procurando traçar as origens de traços culturais tidos como brasileiros desde o nascimento do Brasil até os dias de hoje, sem descrever nuanças ou variações, ao mesmo tempo em que, em maior ou menor grau, os traços culturais aparecem como abrangentes e como sendo característicos de uma unidade denominada "cultura brasileira", com traços típicos exclusivos, tendo sua heterogeneidade desconsiderada e havendo sugestão, implícita ou explícita, de causalidade cultural, no sentido de que esses traços gerariam culturas organizacionais típicas em nosso país. A terceira característica é de que são realizados juízos de valor sobre os supostos traços culturais nacionais, vistos como "subdesenvolvidos" e como causadores do atraso nacional.

$\mathrm{Na}$ continuidade desta parte do artigo, a partir dos ensinamentos da perspectiva pós-moderna, passaremos a problematizar cada um dos aspectos levantados. Primeiro, discutiremos a adequação do uso acrítico de Hofstede para a análise da suposta cultura organizacional brasileira, depois problematizaremos a noção de traços culturais gerais que gerariam uma unidade chamada cultura organizacional brasileira e, por fim, discutiremos os juízos de valor presentes nas análises de nossa cultura.

\section{A adequação de Hofstede}

É evidente que as pesquisas de Hofstede foram im- portantes em determinado contexto histórico da análise organizacional. Porém, será que aceitar sem as devidas problematizações as considerações desse autor é válido para o contexto de nosso país?

Seguimos as considerações de McSweeney (2002) e Palmade (1993), para os quais o modelo de Hofstede parte de pressupostos falaciosos e passa por cima das pluralidades e diversidades dos países que analisa. Parece-nos problemática a divisão de diferentes culturas em dimensões como aversão à incerteza, masculinidade e feminilidade, distanciamento do poder, e individualismo e coletivismo. Ao tentar analisar várias culturas do mundo segundo essas dimensões, o autor está impondo sua visão de mundo e as dimensões que ele considera importantes como forma de análise e como matriz de explicação. Não que acreditemos que haja ciência totalmente livre de juízos de valor e aspectos correlatos, porém, essa é uma forma nítida de generalização que tenta dar conta de uma pluralidade extremamente ampla e diversa, atropelando suas ambigüidades e nuanças a partir de um ponto de vista específico. Isso fica mais patente quando recordamos a visão de cultura para o autor. Para ele, cultura seria "o programa coletivo da mente que distingue os membros de grupos ou categorias de pessoas" (Hofstede, 1991, p. 5). Esse suposto programa mental seria resultante de várias dimensões sociais de influência ou, em seus termos, diferentes níveis de cultura que formariam, em cada indivíduo, diferentes camadas de influência cultural ou programação. Ou seja, cultura seria um programa mental que leva os indivíduos a se comportarem absolutamente em conformidade a padrões grupais. A ação - se é que assim se pode dizer - seria determinada pelo fato de se pertencer a determinado grupo social.

A perspectiva pós-moderna de análise da cultura das organizações (Martin, 1992; Alvesson e Berg, 1992; Alvesson, 1995) entende essa questão de forma diametralmente oposta. A suposição de que a cultura faz com que as pessoas atuem de acordo com algo predeterminado é vista como mais uma simplificação da realidade, já que ambigüidades, pluralidades e peculiaridades individuais são, mais uma vez, atropeladas. Além disso, a definição de cultura acaba por impor uma identidade sobre o sujeito que a ela pertence, ou seja, ele é aprisionado dentro dos limites da cultura, ponto questionado pela perspectiva pós-moderna (Martin, 1992).

Além disso, Hofstede analisa os diferentes países de acordo com as dimensões citadas e os classifica dentro de cada uma delas. Assim, um país pode ter alta ou baixa aversão à incerteza etc. Há, nesse aspecto, uma níti- 
da classificação, dotada de juízo de valor, das diferentes culturas, induzindo à idéia de "melhores" ou "piores" culturas. Trata-se de modelo simplista frente à pluralidade do objeto escolhido. Há clara homogeneização de elementos diferentes que são transpassados e analisados pelo crivo gerado por um autor que nasceu em um país específico, que explica a realidade de acordo com sua visão e a impõe sobre outros países e realidades. Aqui adotamos um espírito neocolonialista, que questiona a criação e a definição de valores gerados em contextos de países desenvolvidos que se impõem sobre os demais, especialmente os não desenvolvidos economicamente (Prasad e Prasad, 2001). Isso não significa que achamos inválido seu estudo, mas queremos apontar que tal homogeneização, utilizada de forma não problematizada por autores brasileiros, simplifica a percepção de nossa pretensa cultura organizacional brasileira, induz a análise de nossa peculiaridade complexa e heterogênea dentro de um ponto de vista gerado alhures e impõe tais valores à nossa realidade.

\section{Traços gerais da cultura organizacional brasileira?}

O segundo aspecto que destacamos é a análise de traços culturais nacionais a partir de suas origens históricas, mostrando que desde o surgimento do Brasil eles estão presentes em nossa sociedade de maneira quase imutáveis. Como dissemos, são utilizadas obras de autores como Sérgio Buarque de Holanda, Caio Prado Jr., Gilberto Freire e Roberto DaMatta para justificar a existência de um estilo brasileiro de administrar, de traços para uma análise organizacional, do estrangeirismo e do paternalismo etc. Quando se toma como base a perspectiva pós-modernista de análise da cultura (Rabinow, 1999) e da cultura nas organizações (Martin, 1992; Alvesson e Berg, 1992), que considera cultura como um fenômeno ambíguo e complexo, repleto de paradoxos e dependente de contextos específicos, torna-se forçoso contrapor generalizações e análises que buscam encontrar coerência histórica em traços culturais. A primeira questão que surge é se tais traços são hoje em dia iguais aos de 500 anos, ou melhor, se o paternalismo presente em uma empresa familiar brasileira é igual ao presente no engenho de açúcar, se o sensualismo é o mesmo presente nas relações entre a casa grande e a senzala e se a adoração ao estrangeiro é a mesma do início do século passado. Ou seja, será que desde 1500 ou 1900 esses traços não mudaram, a despeito das significativas alterações do contexto de nosso país ao longo desses anos? Ou ainda, essas são as características típicas do brasileiro que devem ser levadas em consideração mesmo no contexto e na especificidade atual?

Pressupor continuidade quase absoluta desses termos é pressupor que a realidade não se alterou ou que se alterou dentro de determinadas condições e restrições impostas pela cultura brasileira. Ou seja, a noção de cultura estaria funcionando como infra-estrutura que condiciona tudo o que há dentro de seus domínios. Além disso, esse pressuposto implica que, de norte a sul do país, esses traços continuaram a existir e a influenciar todas as organizações, gerando uma cultura organizacional brasileira, o que reflete aceitação do princípio da causalidade simples.

Como vimos anteriormente, no limite, a grande maioria dos textos que analisam a cultura organizacional brasileira (embora alguns façam ressalvas sobre nossa diversidade) sugere que todos os brasileiros compartilham daqueles traços culturais, que seriam então a fonte de nossa condição de "ser brasileiro".

Como destacamos, essa noção de cultura é rejeitada pelos pós-modernos, já que eles a consideram ambígua por natureza. Ressalta-se veementemente que a cultura não condiciona os sujeitos a serem como ela supostamente designaria. A noção de traços culturais brasileiros ou de estilo brasileiro de administrar seria, então, também um exemplo de narrativa totalizante contra a qual ninguém pode escapar. Naquelas construções, parece estar subjacente a seguinte idéia: se é brasileiro, será, em larga medida, assim. Mais uma vez, nuanças, complexidades e ambigüidades são descartadas e a cultura é compreendida como aquela que impõe o papel que o sujeito deve desempenhar.

Além disso, a suposição de que agrupamentos humanos artificialmente formados, incluídos dentro de fronteiras geográficas, desenvolvam traços culturais que possam ser compartilhados em tal grau que constituam uma cultura, talvez não seja apropriada. Percebendo as contradições dessa perspectiva, o próprio Hofstede (1991, p. 12) reconhece: "Nações não deveriam ser igualadas a sociedades. Historicamente, sociedades são formas organicamente desenvolvidas de organização social, e o conceito de uma cultura comum se aplica, estritamente falando, mais a sociedades do que a nações". Isso nos parece ainda mais problemático quando estamos falando de sistemas sociais como as organizações e de países plurais como o Brasil.

A respeito desse aspecto, se tomarmos como referência antropólogos como Darcy Ribeiro (1995), autor utilizado pelos que pesquisam e estudam a cultura organizacional brasileira, o Brasil - não sem razão - deve ser 
reconhecido como culturalmente múltiplo, sendo isso um fato enriquecedor de nossa nacionalidade. Nessa mesma linha, Bosi (1992, p.1) destaca que: "Da cultura brasileira já houve quem a julgasse ou a quisesse unitária, coesa, cabalmente definida por essa ou aquela qualidade mestra (...) ocorre, porém, que não existe uma cultura brasileira homogênea, matriz dos nossos comportamentos e dos nossos discursos. Ao contrário: a admissão de seu caráter plural é um passo decisivo para compreendê-la como efeito de sentido, resultado de um processo de múltiplas interações e oposições no tempo e no espaço (...) A cultura das classes populares, por exemplo, encontra-se, em certas situações, com a cultura de massa; esta com a cultura erudita e vice-versa. Há imbricações de velhas culturas ibéricas, indígenas e africanas, todas polimorfas, pois já traziam um teor considerável de fusão".

Vale frisar também que a noção de traços característicos de nossa cultura, que possuem origens históricas claras, implica reconhecer que são nossos, que são brasileiros. Porém, será que venezuelanos, argentinos, chilenos, angolanos, sul-africanos não são, por exemplo, paternalistas, não adoram o estrangeiro e não são sentimentalistas, nos termos defendidos pelos analistas da cultura organizacional brasileira?

De fato, parece não estar patente na teoria organizacional brasileira que qualquer "teorização" das origens e características de um povo, enquanto fonte de sua identidade, possui importância política significativa. Isso já foi há muito ressaltado por Guerreiro Ramos quando propôs a redução sociológica das explicações oriundas de outros contextos para entender a realidade nacional. Construindo sua proposta de estudo cultural a partir da filosofia heideggeriana, Ramos (1996, p. 86-87) defende que "um objeto cultural é constituído não só por seus elementos objetivos, mas também pela função que exerce no sistema de objetos de que faz parte. Para efeito de redução sociológica, a função dos objetos é entendida (...), em termos de sentido, de acordo com a intencionalidade que possuem em uma estrutura referencial". Os supostos traços gerais da cultura brasileira podem, por exemplo, possuir diferentes significados, ser produto de diferentes intenções e ocupar diferentes funções em diferentes grupos da cultura. Sua suposta manifestação generalizada pode, em conformidade com essa perspectiva, não ser mais do que produto de análises superficiais que ressaltam a aparência em detrimento do significado local da manifestação.

A generalização de padrões culturais, portanto, quando a analisamos inspirados pela perspectiva pós- moderna, constitui-se em artifício de poder, porque implica o silêncio ou mesmo a exclusão de indivíduos e grupos não representados na "cultura oficial", ou cujos traços não correspondam àqueles tomados oficialmente como marcas do grupo ou do país. Não é de se estranhar que nos estudos de Barros e Prates (1996, 1997) os autores apontem a postura de espectador como traço dos trabalhadores brasileiros, quando se observa que em sua pesquisa foram entrevistados somente os "executivos" das regiões Sul e Sudeste do Brasil. Ou seja, o estilo brasileiro não é brasileiro, mas sim de um grupo específico em duas regiões geográficas específicas. A noção de que o trabalhador brasileiro possui postura de espectador vai frontalmente contra estudos que retratam a cultura popular, especialmente de trabalhadores, como locus da resistência e do questionamento velado (Chauí, 1986).

Pelo que acabamos de ver, a perspectiva pós-moderna mostra-nos as contradições inerentes nos estudos de cultura das organizações brasileiras e permite-nos indagar e questionar, usando referenciais modernos que discutem a cultura brasileira, a validade de assertivas que sugerem generalizações e verdades sobre um país plural, com formação tão diversa e heterogênea quanto o nosso.

\section{A cultura organizacional que não presta}

O último traço que destacamos dos estudos organizacionais brasileiros é o de que neles predomina uma visão negativa da suposta cultura brasileira em relação a outras culturas, principalmente a norte-americana ou a de países considerados desenvolvidos (o Japão é outro exemplo recorrente). Identifica-se claramente nessas análises a forte influência dos primeiros estudos culturalistas desenvolvidos no Brasil, em especial de Buarque de Holanda e sua proposição da natureza cordial do brasileiro típico. Mas, como destaca Souza (1999), a construção teórica de Holanda, fundamentada na teoria weberiana de racionalização ocidental, tem como objetivo construir um tipo absolutamente negativo de personalidade, o homem cordial brasileiro, em comparação ao tipo absolutamente positivo do protestante ascético norte-americano tomado da obra weberiana. As características resultantes desse esforço de análise típico-ideal são o individualismo personalista, a busca de prazeres imediatos, descaso por ideais comunitários e de longo prazo.

Explica-se, portanto, o atraso brasileiro em relação ao desenvolvimento econômico norte-americano como resultante dessa tradição cultural na formação do povo brasileiro: "Apenas o homem cordial é concebido como 
negatividade pura, entidade amorfa dominada pelo conteúdo emotivo imediato e pela necessidade desmedida de reconhecimento alheio. Como resultado (...) não temos aqui nem mercado capitalista moderno nem democracia digna desse nome" (Souza, 1999, p. 35). A construção teórica aqui, ressalta-se novamente, tem caráter de tipo ideal e se refere à tentativa de Buarque de Holanda em revelar uma personalidade ideal oposta ao protestante ascético weberiano e, assim, fornecer explicação para a superioridade econômica dos valores protestantes. Em outras palavras, é a busca por representação de tendências ou heranças culturais, mas não de características culturais empiricamente observáveis em seu todo.

É o que ressalta Vianna Moog em estudo que parte da tradição iniciada por Buarque de Holanda. Moog (1974) é mais enfático em destacar os objetivos dessa linha analítica, isto é, a comparação dos tipos de personalidade ou tipos culturais - brasileiro versus protestante ascético norte-americano - limitada à dimensão econômica e à sua adequação a parâmetros relativos às características da modernidade ocidental.

Faz-se necessário, portanto, que se contextualize essa crítica pelo aspecto econômico, ou seja, que se tenha claro que é em relação ao contexto moderno de competição capitalista que essa suposta herança cultural apresenta desvantagens, mas não de forma geral. Além disso, há de se aceitar como legítima a estrutura capitalista de sociedade para que se considere também legítima essa superioridade, e é aí que está o caráter de verdade única disfarçado em significativa parte das análises culturalistas da sociedade brasileira, construídas no âmbito de nossa teoria organizacional. Como aponta Werneck Vianna (1998, p. 175): "O Weber da versão hoje hegemônica nas Ciências Sociais e na opinião pública sobre a interpretação do Brasil, tem sido aquele dos que apontam nosso atraso como resultante de um vício de origem, em razão do tipo de colonização a que fomos submetidos - a chamada herança do patrimonialismo ibérico...".

Assim, é recorrente nos estudos organizacionais apontar a natureza personalista das relações sociais no Brasil como sendo aspecto negativo para o desenvolvimento profissional e organizacional. Sugere-se freqüentemente que a cooperação entre nós seja sempre produto de relações afetivas, voltadas à busca de favores pessoais em detrimento da sociedade ou do grupo mais amplo e em detrimento de relações baseadas na impessoalidade. Entretanto, não se discutem as conseqüências dessa confiança baseada em impessoalidade, ou confiança em sistemas abstratos: a necessidade de aceitação compulsória - isto é, sem alternativas - do conhecimento especializado, a perda de valor do conhecimento local, a disseminação, universalização e institucionalização do risco, entre outros (Giddens, 1991; Giddens, Beck e Lash, 1997). O personalismo que seria típico do brasileiro é confundido com o desejo de "levar vantagem em tudo", como se a apropriação pessoal do lucro e das vantagens do sistema produtivo não fosse, em si, característica do capitalismo. Em resumo, a impessoalidade nas relações é considerada benéfica e superior em termos absolutos. É interessante que, na busca por identificar traços da cultura brasileira e, assim, promover modelos de gestão adaptados à realidade nacional, acaba-se por emitir julgamentos de valor provenientes de outras realidades, ou seja, julga-se nossa suposta cultura por meio de lentes estranhas à nossa realidade. A perspectiva neocolonialista ajuda-nos a perceber como nós mesmos criamos nossa própria exclusão por meio de conceitos que não levam em conta nossa realidade e exclui as vozes destoantes e as complexidades (Prasad e Prasad, 2001).

Voltemo-nos a Darcy Ribeiro (1995, p. 269), para quem os núcleos culturais formadores de nosso país (os Brasis) eram ao mesmo tempo muito iguais e muito diferentes: "a história, na verdade das coisas, se passa nos quadros locais, como eventos que o povo recorda e a seu modo explica. É aí, dentro das linhas de crenças coparticipadas, de vontades coletivas abruptamente eriçadas, que as coisas se dão". Podemos admitir, por meio da perspectiva de análise pós-moderna, que ressaltar as igualdades e silenciar as diferenças é, por si, opção que descontextualiza e atropela ambigüidades e complexidades inerentes a qualquer cultura. Ressaltar apenas alguns daqueles aspectos é, no mínimo, generalizar uma caracterização que normalmente descaracteriza, ainda que seja para que se possa, de alguma forma, ordenar uma compreensão ou interpretação qualquer de nossa realidade nacional.

\section{CONSIDERAÇÕES FINAIS}

Neste artigo, procuramos problematizar a produção acadêmica que analisa a denominada "cultura organizacional brasileira" na área de estudos organizacionais e administração. Vimos que, em termos gerais, essa produção possui algumas características recorrentes. A primeira delas é de que tal produção foi influenciada de forma marcante pela pesquisa de Hofstede, cujos pre- 
ceitos são aceitos de forma não problematizada pela vasta maioria dos estudos que analisamos. A segunda consideração é de que, em sua maioria, os textos analisados recorrem à análise de traços culturais nacionais a partir de suas origens históricas, procurando descrever sua continuidade desde a formação do Brasil até os dias de hoje, sem apontar nuanças ou variações. Ao mesmo tempo, em maior ou menor grau, tais traços culturais aparecem como abrangentes, típicos, exclusivos e característicos de uma unidade denominada "cultura brasileira". Assim, a heterogeneidade da cultura brasileira é renegada ao segundo plano. A terceira consideração é de que são realizados juízos de valor sobre os supostos traços culturais nacionais, vistos como "subdesenvolvidos" e como causadores do atraso nacional.

Problematizando os pontos que acabamos de levantar a partir da perspectiva pós-moderna, discutimos a inadequação do uso direto do referencial de Hofstede e os problemas associados à noção de uma cultura organizacional brasileira, pois tal noção passa por cima de nuanças, especificidades e peculiaridades regionais, locais e individuais. Por fim, discutimos o juízo de valor presente em boa parte dos estudos que analisam a cultura organizacional brasileira.

O resultado das análises que se realizaram neste artigo aponta à possibilidade de que os estudos culturais no âmbito da teoria organizacional sejam mais específicos, locais e referentes a grupos culturais. Uma perspectiva desse tipo implica reconhecer o fundamento e as consequêencias políticas da análise cultural, ao mesmo tempo em que implica uma análise mais descritiva do fenômeno cultural. De fato, as abordagens ao fenômeno da cultura, tanto quanto a interpretação da cultura organizacional, em sua maioria, revelam que ainda predomina na administração brasileira um viés fortemente gerencialista e pretensões de engenharia social, constituindo instrumento a favor de grupos dominantes ou privilegiados, de algum modo.

Muito embora a discussão da noção de cultura organizacional brasileira seja de fundamental importância para o desenvolvimento de análises que façam mais sentido dentro de nossa peculiaridade, a preocupação com especificidades e contextos que são extremamente plurais é de fundamental importância para levarmos em conta o que de mais importante há na sociedade brasileira: a heterogeneidade. Quando essa heterogeneidade não é considerada apropriadamente ou é silenciada, acabamos por analisar nosso país e nossas organizações de forma superficial, ao mesmo tempo em que desenvolve- mos estudos e pesquisas que funcionam como esforço de retórica para a afirmação de uma falaciosa identidade nacional única. Trilhando esse caminho, continuaremos a falar de um Brasil que só existe nas improváveis generalizações que realizamos.

Artigo recebido em 14/05/2002. Aprovado em 09/10/2002.

\section{Referências bibliográficas}

AIDAR, M; BRIZOLA, A; PRESTES MOTTA, F. e WOOD JR., T. Cultura organizacional brasileira. In: WOOD Jr., T. Mudança organizacional. São Paulo : Atlas, 1995.

ALVESSON, M. Cultural perspectives on organizations. New York : Cambridge University Press, 1995.

ALVESSON, M. e BERG, P. Corporate culture and organizational symbolism. Berlin : de Gruter, 1992.

BARROS, B. e PRATES, M. O estilo brasileiro de administrar. São Paulo : Atlas, 1996.

BARROS, M. Um estudo comparado sobre gestão emancipadora em organizações comunitárias: a comparação Bahia (Brasil) e Québec (Canadá). In: ENCONTRO ANUAL DA ASSOCIAČ̃̃O NACIONAL DOS PROGRAMAS DE PÓS-GRADUAÇÃO EM ADMINISTRAÇÃO, 25ㅇ, 2001, Campinas. Anais eletrônicos... ANPAD, 2001.

BAIARDI, A. Padrões culturais e resistência a mudanças: obstáculos à democracia e ao desenvolvimento no Brasil. Organização e Sociedade, Jul. 1996.

BARDIN, Laurence. Análise de conteúdo. Lisboa: Edições 70, 1977.

BAUMAN, Z. Viewpoint: sociology and postmodernity. Sociological Review, v. 36, n. 6, 1988a.

BAUMAN, Z. Is there a postmodern sociology? Theory, Culture and Society, v. 5, n. $2,1988 b$ 
BORGES DE FREITAS, A. Traços para uma análise organizacional. In: PRESTES MOTTA, F. e CALDAS, M. Cultura organizacional e cultura brasileira. São Paulo : Atlas, 1997.

BOSI, A. Cultura brasileira: temas e situações. São Paulo : Ática, 1992.

BRESLER, R. O pai e as organizações: práticas de poder no Brasil. Organização e Sociedade, v. 7, n. 18, 2000.

CALÁS, M. e SMIRCICH, L. Past posmodernity? Reflections and tentative directions. Academy of Management Review, v. 24, n. 4, 1999.

CALDAS, M. Santo de casa não faz milagre: condicionantes nacionais e implicações organizacionais da fixação brasileira pela figura do "estrangeiro". In: PRESTES MOTTA, F. e CALDAS, M. Cultura organizacional e cultura brasileira. São Paulo : Atlas, 1997.

CALLIGARIS, C. Hello Brasil. São Paulo: Escuta, 1993.

CAMPOS, C. A competitividade e o aprendizado das organizações brasileiras. Revista de Administração Pública, v. 34, n. 3, 2000.

CAPELÃO, F. Relações de poder no processo de sucessão em empresas familiares: o caso das indústrias Filizola S.A. Organização e Sociedade, v. 7 , n. 18,2000 .

CARBONE, P. Cultura organizacional do setor público brasileiro: desenvolvimento de uma metodologia de gerenciamento da cultura. Revista de Administração Pública, v. 34, n. 2, 2000.

CAVEDON, N. As culturas das organizações brasileiras na era da globalização. In: ENCONTRO ANUAL DA ASSOCIAÇÃO NACIONAL DOS PROGRAMAS DE PÓS-GRADUAÇÃO EM ADMINISTRAÇÃO, 22º , 1998, Foz do Iguaçu Anais eletrônicos... ANPAD, 1998.

CHAUÍ, M. Conformismo e resistência. São Paulo : Brasiliense, 1986.

CLEGG, S. Modern Organizations. London: Sage, 1990.

CLIFFORD, J e MARCUS, G. Writing Culture: The Poetics and Politics of Ethnography. Berkley: University of California Press, 1986.

COOPER, R e BURRELL, G. Modernism, postmodernism and organization analysis: an introduction. Organization Studies, v. 9, n. 1, 1988

COSTA, A Cultura brasileira e organização cordial: ensaio sobre a Gaviões da Fiel. In: Prestes Motta, F. e Caldas, M. Cultura organizacional e cultura brasileira. São Paulo : Atlas, 1997.

DAVEL, E. e VASCONCELOS, J. Gerência e autoridade nas empresas brasileiras: uma reflexão teórica e empírica sobre a dimensão paterna nas relações de trabalho. In: PRESTES MOTTA, F. e CALDAS, M. Cultura organizacional e cultura brasileira. São Paulo : Atlas, 1997.

FEATHERSTONE, M. In pursuit of the postmodern: an introduction. Theory, Culture and Society, v. 5, n. 2, 1988.

FOUCAULT, M. As palavras e as coisas. Lisboa : Portugalia, 1966.

FOUCAULT, M. História da sexualidade. Rio de Janeiro : Graal, 1987. Vol. I - A vontade de saber.
GIDDENS, A. As conseqüências da modernidade. São Paulo: Unesp, 1991.

GIDDENS, A.; BECK, U.; LASH, S. Modernização reflexiva. São Paulo: Editora Unesp, 1997.

GONÇALVES DA SILVA, V. Antropologia pós-moderna - guia prático de sobrevivência. São Paulo : USP, 2001. Mimeo.

GOPAL, WILLIS e GOPAL, 1999.

HABERMAS, J. Modernity versus postmodernity. New German Critique, n. 22, p. 3-18, Winter, 1981

HASSARD, J. Sociology and organization theory. New York : Cambridge University Press, 1993.

HATCH, M. J. Organization theory: modern, symbolic and postmodern perspectives. Oxford: Oxford University Press, 1997.

HOFSTEDE, G. Culture's consequences: international differences in workrelated values. 2nd ed. Beverly Hills : Sage, 1980.

HOFSTEDE, G. Cultures and organizations: software of the mind. New York : McGraw-Hill, 1991.

LYOTARD, J. La condicion postmoderna. Madrid : Catedra, 1989.

MARTIN, J. Cultures in organizations: three perspectives. Oxford : Oxford University Press, 1992

MARTIN, J. e FROST, P. Jogos de guerra da cultura organizacional: a luta pelo domínio intelectual. In: CLEGG, S.; HARDY, C. e NORD, W. Handbook de estudos organizacionais. São Paulo : Atlas, 2001.

MCSWEENEY, L. Hofstede's model of national cultural differences. Human Relations, v. 55, n. 1, p. 88-117, 2002.

MOOG, V. Bandeirantes e pioneiros. $11^{\mathrm{a}} \mathrm{ed}$. Porto Alegre : Globo, 1974.

PALMADE, J. Lê management interculturel. L'effacement dês bases identitaries. In: Palmade, J. Lês deux sources de l'exclusion, economisme et replis identitaires. Paris : Editions Karthala, 1993.

PARKER, M. Post-Modern organizations or postmodern organization theory. Organization Studies. v. 13, n. 1, p. 1-17, 1992.

PRASAD, A. e PRASAD, P. Otherness at large: identity and difference in the new globalized organizational landscape. In: MILLS, A. e MARJOSA, I. Gender, identity and culture of organizations. London : Rotledge, 2001.

PRESTES MOTTA, F. Cultura e organizações no Brasil. In: Prestes Motta, F. e Caldas, M. Cultura organizacional e cultura brasileira. São Paulo : Atlas, 1997.

PRESTES MOTTA, F. e ALCADIPANI, JeitinhoBrasileiro, Controle Social e Copetição. Revista de Admistração de Empresas, vol. 39 no. 03. 1999. 
PRESTES MOTTA, F; ALCADIPANI, Re BRESLER, R. Estrangeirismo como Segregação nas Organizações. Revista de Administração Contemporânea. Vol. 05. Número Especial ENEO, 2001

PRESTES MOTTA, F. e CALDAS, M. Cultura organizacional e cultura brasileira. São Paulo: Atlas, 1997.

RAMOS, A. G. A redução sociológica. Rio de Janeiro : Editora da UFRJ, 1996.

RABINOW, P. Antropologia da razão. Rio de Janeiro : Relume Dumará, 1999.

RIBEIRO, Darcy. O povo brasileiro: a formação e o sentido do Brasil. São Paulo : Companhia das Letras, 1995.

SANTOS, J. Paratodos Bahia: uma organização no jogo do bicho. Organização e Sociedade, Jun. 1996.

SOKAL, A. e BRICMONT, J. Fashionable nonsense: postmodern intellectuals' abuse of science. New York : Picador USA, 1999.
SOUZA, J. A ética protestante e a ideologia do atraso brasileiro. In: Souza, J. (Org.). O malandro e o protestante: a tese weberiana e a singularidade cultural brasileira. Brasília : UnB, 1999. p. 17-54.

THOMPSON, P. Postmodernism: fatal distraction. In: Hassard, J. e Parker, M. Postmodernism and organizations. London: Sage, 1993. p. 183-203.

URDAN, F. T. e URDAN, A. T. Estilos gerenciais e agrupamento de cultura nacional: brasileiros versus europeus latinos e anglo-saxões. In: ENCONTRO ANUAL DA ASSOCIAÇÃO DOS PROGRAMAS DE PÓS-GRADUAÇÃO EM ADMINISTRAÇÃO, 25ㅇ, 2001, Campinas. Anais eletrônicos... São Paulo : ANPAD, 2001.

VERGARA, S.; MORAES, C. e PALMEIRA, P. Cultura brasileira revelada no barracão de uma escola de samba: o caso da família Imperatriz. In: PRESTES MOTTA, F. e CALDAS, M. Cultura organizacional e cultura brasileira. São Paulo : Atlas, 1997.

VIANNA, L. W. Weber e a interpretação do Brasil. In: Souza, J. (Org.). O malandro e o protestante: a tese weberiana e a singularidade cultural brasileira. Brasília : UnB, 1999. p. 173-94.

\section{Rafael Alcadipani}

Professor do Departamento de Administração Geral e Recursos Humanos da FGV-EAESP e professor da ESPM-SP. Mestre em Administração pela FGV-EAESP. Interesses de pesquisa em teoria crítica das organizações e perspectivas pós-estruturalistas em análise das organizações.

E-mail: ralcadipani@fgvsp.br

Endereço: FGV-EAESP. Av. 9 de julho, 2029. São Paulo, SP. CEP 01313-902.

\section{João Marcelo Crubellate}

Professor do Departamento de Administração da Universidade Estadual de Maringá (PR)-UEM.

Doutorando em Administração de Empresas pela FGV-EAESP. Interesses de pesquisa em Teoria das Organizações e em Gestão Ambiental.

E-mail: jmcrubellate@aol.com

Endereço: DAD/UEM. Av. Colombo, 5970. Maringá, PR. CEP 87020-900. 